\title{
Attitude of Extension Professionals Towards Agri-Expert Systems
}

\author{
Modem Ravikishore ${ }^{*}$, Reeba Jacob and Allan Thomas
}

Dept. of Agricultural Extension, College of Agriculture, Vellayani, Trivandrum, Kerala (695 522), India

\section{Article History}

Manuscript No. AR1545

Received in $27^{\text {th }}$ November, 2015

Received in revised form $29^{\text {th }}$ March, 2016

Accepted in final form $5^{\text {th }}$ April, 2016

\section{Correspondence to}

*E-mail: mrks777143@gmail.com

\section{Keywords}

Agriculture, agri-expert system, attitude, extension professional

\begin{abstract}
It has been suggested that 'agri-expert systems' might have a significant role in the future by enabling large number of people so that they can access human experts. It is, therefore, important to understand how potential users interact with these computer systems. This study investigates the extension professionals' attitude towards the use of Kerala Agricultural University (KAU) expert systems for fertilizer recommendation, pest, disease diagnosis, and management of weeds in crop fields. The study also depicts the factors affecting the attitude of extension professionals. A survey was conducted among three targeted segments of Kerala's extension professionals with a sample of 100 respondents actively involved in the field of agriculture to evaluate questions about the attitude of respondent in using agri-expert systems. It also aims to depict the factors which are affecting the attitudes of extension professionals. Results showed that the extension professionals' attitude towards agri-expert systems was generally moderately favorable and the factors such as Training, Innovative proneness and Information content were positively and significantly related with the attitude towards expert systems among all three categories of respondents. In order to improve the extension professionals' attitude towards expert systems, information content available in the expert system should be up to date and addresses the problems which are location specific and need specific. There is also greater need to enrich extension professionals' knowledge about the innovative applications of expert systems by conducting suitable training programmes in a timely manner for the benefit of farming community and effective agriculture decision making.
\end{abstract}

\section{Introduction}

Agricultural extension is an essential mechanism for delivery of knowledge as an input for modern farming (Jones, 1997). Perceiving the needs and demands of technologies, the extension network has been launched countrywide to disseminate the newer technologies. Yet, it was an imbroglio, that whether the available services could meet these needs with the existing scarce financial and human resources. Rolling (1980) mentioned, that "unfortunately many extension professionals have been trained too narrowly and focus on technology and its introduction. Thus they miss many opportunities for helping their clients as well as missing out a lot of exciting aspects of rural extension and intervention through communication". It is in this juncture the hall mark in the development of telecommunications and computerbased information technology in the era of globalization probably would be the best alternative and rather means for see change in extension. This is possible with the use of agri- expert systems which can make agricultural extension a more diversified, knowledge driven system for meeting on demand farmer's information needs. Artificial intelligence programs that achieve expert level competence in solving problems in task areas by bringing to bear a body of knowledge about specific task are called expert systems (Nitin et al., 2013). The agri-expert system is based on agriculture related problem solving models, diagnostics model, prediction model and farm management model (Patterson, 2004). Extension professionals constantly encounter and are well aware of the impacts that technological innovations have on individuals. A major technology utilizing the clientele of extension professionals today is the agri-expert system. Major shifts are underway in the way information is accessed by agricultural extension agents, including a diversification of channels through which they receive information (Abdel-wahed, 2007). Hence, in order to make prudential and accurate decisions, farm managers/ extension workers/farmers need speedy access to expert system for advice on agricultural problems which could be timely, 
reliable and consistent.

Anand and Ravichandran (2014) state that majority of the extension personnel had moderately favorable attitude towards ICT tools. Shashaani (1994) observed that recent empirical studies demonstrated positive relation between computer experience and attitudes towards computer. Ndubisi (2004) reported that attitude towards e-learning model will be positively influenced by the perceived usefulness of expert system and the ease of their use. Literature suggests that extension agent's attitude towards the use of agri-expert system and its determinants, their belief with regard to using agri-expert system, and their evaluation of expected outcomes from using agri-expert system, were all positive or favorable (Chetsumon, 2005). Amir (2012) reported that extension workers' attitude towards e-learning is generally positive and in most aspects relevant to the learners' prior experience. The researchers who are involved in developing agricultural expert system generally conduct validation studies to ensure the precision of knowledge base provided in the system. Unfortunately, research studies in assessing the attitude of extension professionals towards agri-expert systems are limited. The factors which affect the attitude of extension professionals have also been a neglected area. With a construal to augment the attitude of extension professionals towards agri-expert systems, a systematic appraisal was studied on-a) existing expert systems in agriculture vis-a-vis attitude of extension professionals towards expert systems, and b) the relationship between attitude of the respondents with their personal factors and expert system's attributes.

\section{Materials and Methods}

A survey was conducted using pre tested and structured questionnaire during 2012-2014 among three targeted segments of Kerala extension professionals to evaluate questions about the attitude of respondents towards agri-expert systems and its features for the benefit of farming community and effective agriculture decision making. Respondents were selected through simple random sampling from entire Kerala state. The sample of the study constituted of 100 respondents- 40 extension professionals consisting of Agricultural Officers (AO's), 30 front line extension professionals of KVK's (Krishi Vigyan Kendra's) and NGO's (Non-Governmental Organization's) actively involved in the field of agriculture and 30 Scientists involved in the extension programmes of Kerala Agricultural University, ICAR (Indian Council of Agricultural Research) Institutes and Commodity Boards.

Attitude was operationalized as the degree of positive or negative affect associated with expert systems. The scale was constituted of 14 statements, 7 positive and 7 negative. The scoring pattern was followed in 5 point continuum as given below (Table 1).

The study conducted with special reference to Kerala Agricultural University expert systems i.e., KAU- Fertulator which can be used for fertilizer calculation and e-Crop Doctor for pest, disease and weed management, to determine the attitude of extension professionals towards expert systems for decision-making. Based on the total scores, the respondents were classified into 3 categories using quartiles, as measure of check (Table 2).

The study also depicts the influence of respondent's personal attributes and expert system's attributes on the attitude of respondents towards expert system by simple correlation analysis.

Respondent's personal attributes and expert system's attributes was followed as

- Age: It was operationalized by considering the chronological age of the extension personnel in completed years at the time of investigation.

- Education: Education was operationalized as the number of years of formal schooling obtained by the extension personnel.

- Training: Training refers to the no. of times training received by the respondents on ICT tools.

- Innovativeness: It refers to the behavioral pattern of an individual who has interest and desire to seek changes in ICT tools and ready to introduce such changes which are practical and feasible.

- Availability: Availability was operationalized as the ICT offered with reasonable proximity and appropriate hardware and software.

- Accessibility: It refers to the ability to access the expert system.

- Retrievability: It was operationalized as the extent to which

\begin{tabular}{lcc}
\hline \multicolumn{3}{l}{ Table 1: Scoring pattern of statements } \\
\hline Category & $\begin{array}{c}\text { For positive } \\
\text { statements }\end{array}$ & $\begin{array}{c}\text { For negative } \\
\text { statements }\end{array}$ \\
\hline Strongly disagree & 1 & 5 \\
Disagree & 2 & 4 \\
Undecided & 3 & 3 \\
Agree & 4 & 2 \\
Strongly agree & 5 & 1 \\
\hline \multicolumn{3}{l}{ Table 2: Categorization of respondents } \\
\hline Category & Quartile classification \\
\hline Unfavourable & Less than Quartile deviation 1 \\
Moderately favourable & Between $\mathrm{Q}_{1}-\mathrm{Q}_{3}$ \\
Favourable & More than Quartile deviation 3 \\
\hline
\end{tabular}


the information provided in the system can be easily located and received by any user.

- Relevancy: It was operationalized as the opinion of the respondents about the suitability of the information provided in the agricultural expert system to the users' situation. It was assessed whether the system was able to provide information suitable to the users' and appropriate to the users' needs.

- Format clarity: It was operationalised as the extent to which the information given is in clear format which help the receiver to arrive at a decision.

- Information content: Information content was measured as the extent to which the information on the subject matter was covered in the expert system. It was assessed whether the provided information was complete to the users.

- Timeliness: This was operationalized as the information provided when it is needed.

- Accuracy: It was operationalized as the quality of information being near to the true value.

\section{Results and Discussion}

The completed and returned questionnaires from our sample of respondents revealed that $61 \%$ respondents possessed moderately favourable attitude towards agri-expert system, $21 \%$ possessed favourable attitude towards agri-expert systems and $18 \%$ possessed unfavourable of attitude towards agriexpert systems (Table 3).

Perusal of the Table 3 further revealed that the extension professionals of FLEP from KVK and NGO's possessed moderately favourable attitude with the highest percentage (63.33\%) when compared to EP from SDA (State Department of Agriculture) and Scientists of Institutes. Scientists of institutes possessed favourable attitude towards agri-expert systems with the highest percentage (30\%) followed by FLEP from KVK and NGO's with the percentage (23.33\%) and EP from SDA with the percentage $(12.5 \%)$ respectively. This might be because agri-expert system had the potential of transferring knowledge from scientists to extension workers and in turn to farmers. They also agreed that agri-expert system had the potential of reducing the time gap of transferring technologies from scientists to farmers and the distortion of message in transfer of technologies from researchers to users.

A detailed and careful perusal of Table 3 further revealed that comparing favourable attitude respondents from all three categories, majority of the scientists possessed favourable attitude towards expert systems. This might be because scientists themselves involved in developing agri-expert systems for the benefit of farming community. Comparing moderately favourable attitude respondents from all three categories, majority of the FLEP from KVK and NGO's possessed moderately favourable attitude towards expert systems than EP from SDA and Scientists of Institutes. This might be because they were more interested in using agriexpert systems technology for solving farmer's problems and they perceived that accessibility, availability, relevancy, retrievability, accuracy, timeliness, format clarity and information content of the expert system were relatively high in KAU expert systems and it would not need any expertise to operate and also available in off-line. This study showed that extension professionals' attitude towards agri-expert systems was generally moderately favourable. The strong positive attitude towards agri-expert systems is an opportunity to develop e-Agricultural Extension Technology (e-AET) in agricultural extension.

An agri-expert system is supposed to yield larger benefits only if it is designed and carried out effectively for which development of effective tools sound high. Any tool can be effective if it is able to create desired changes in knowledge, knowledge related to skill and attitude of the users. There were so many agri-expert systems developed by ICAR institutes and state agricultural universities. Faced with these opportunities, agricultural universities are eager to explore the potential of agri-expert system and avoid existing pitfalls. Although

\begin{tabular}{|c|c|c|c|c|c|c|c|c|}
\hline \multirow[t]{2}{*}{ Category } & \multicolumn{2}{|c|}{ EP from SDA. $(\mathrm{N}=40)$} & \multicolumn{2}{|c|}{$\begin{array}{l}\text { FLEP from (KVK and } \\
\text { NGO's) }(\mathrm{N}=30)\end{array}$} & \multicolumn{2}{|c|}{$\begin{array}{c}\text { Scientists. } \\
(\mathrm{N}=30)\end{array}$} & \multicolumn{2}{|c|}{$\begin{array}{c}\text { Total } \\
(\mathrm{N}=100)\end{array}$} \\
\hline & No. & $\%$ & No. & $\%$ & No. & $\%$ & No. & $\%$ \\
\hline${\text { Unfavourable }\left(<\text { Quartile }_{1}\right)}$ & 11 & 27.5 & 4 & 13.33 & 3 & 10 & 18 & 18 \\
\hline Moderately favourable $\left(\mathrm{Q}_{1}-\mathrm{Q}_{3}\right)$ & 24 & 60 & 19 & 63.33 & 18 & 60 & 61 & 61 \\
\hline Favourable $\left(>\right.$ Quartile $\left._{3}\right)$ & 5 & 12.5 & 7 & 23.33 & 9 & 30 & 21 & 21 \\
\hline Quartiles under each class of respondents & $\begin{array}{c}\text { Quartile }_{1}-55 \\
\text { Quartile }_{2}-57.5 \\
\text { Quartile }_{3}-62\end{array}$ & $\begin{array}{l}\text { Quartile }_{1}-54 \\
\text { Quartile }_{2}-56 \\
\text { Quartile }_{3}-58\end{array}$ & $\begin{array}{c}\text { Quartile }_{1}-55 \\
\text { Quartile }_{2}-56 \\
\text { Quartile }_{3}-57.5\end{array}$ & & & & & \\
\hline
\end{tabular}

EP: Extension Professionals; SDA: State Department of Agriculture; FLEP: Front Line Extension Professionals; KVK: Krishi Vigyan Kendra; NGO: Non Governmental Organisations. 
most of the respondents had moderately favourable attitude towards KAU expert system, still there were respondents with unfavourable attitude towards agri-expert systems. Hence, for the betterment of farming community attitude of extension professionals towards agri-expert systems should be transformed into an affirmative fashion. This can be done by improving expert systems with respect to location specific, need based and updated information on real time basis with lot of credibility and understandability in a sustainable way. This finding differs from the results of Chetsumon (2005) that extension agent's attitude towards the use of agri-expert system and its determinants and their belief with regard to using agriexpert system were all positive or favorable.

\subsection{Relationship between attitude of respondents and personal factors and expert system's attributes}

The results of simple correlation analysis were taken into consideration for analysing the influence of respondent's personal attributes/characteristics and expert system's attributes on the attitude of respondents towards expert system (Table 4).

The results of correlation analysis are presented in Table 4 . Correlation analysis revealed that out of 12 personal factors and expert system's attributes, three factors namely, Training,

Table 4: Results of correlation between attitude of extension professionals of State Department of Agriculture, front line extension personnel of NGO's and KVK's and scientists of agricultural research institutes and personal and expert system's attributes

\begin{tabular}{llccc}
\hline Sl. & $\begin{array}{l}\text { Personal at- } \\
\text { no. }\end{array}$ & \multicolumn{3}{c}{ Correlation co-efficient 'r' value } \\
\cline { 2 - 5 } & $\begin{array}{l}\text { expert system's } \\
\text { attributes }\end{array}$ & $\begin{array}{c}\text { Extension } \\
\text { professionals } \\
\text { (AO's) }\end{array}$ & $\begin{array}{c}\text { Front line } \\
\text { extension }\end{array}$ & Scientists \\
personnel & \\
\hline $\mathrm{X}_{1}$ & Age & -0.246 & 0.277 & 0.057 \\
$\mathrm{X}_{2}$ & Education & -0.169 & 0.145 & 0.202 \\
$\mathrm{X}_{3}$ & Training & $0.509^{* *}$ & $0.673^{* *}$ & $0.569^{* *}$ \\
$\mathrm{X}_{4}$ & Innovativeness & $0.686^{* *}$ & $0.684^{* *}$ & $0.688^{* *}$ \\
$\mathrm{X}_{5}$ & Availability & 0.091 & $0.768^{* *}$ & $0.722^{* *}$ \\
$\mathrm{X}_{6}$ & Accessibility & 0.049 & 0.298 & $0.508^{* *}$ \\
$\mathrm{X}_{7}$ & Retrievability & 0.091 & 0.257 & 0.282 \\
$\mathrm{X}_{8}$ & Relevancy & 0.309 & $0.551^{* *}$ & 0.296 \\
$\mathrm{X}_{9}$ & Format clarity & 0.006 & 0.362 & 0.216 \\
$\mathrm{X}_{10}$ & Information & $0.510^{* *}$ & $0.584^{* *}$ & $0.641^{* *}$ \\
& content & & & \\
$\mathrm{X}_{11}$ & Timeliness & 0.030 & $0.730^{* *}$ & $0.629^{* *}$ \\
$\mathrm{X}_{12}$ & Accuracy & 0.299 & $0.571^{* *}$ & $0.581^{* *}$ \\
\hline
\end{tabular}

"Significant at 0.05 level of probability; ${ }^{* *}$ Significant at 0.01 level of probability
Innovative proneness and Information content were positively and significantly related with extent of attitude towards expert systems among all three categories of respondents viz., Extension professionals of state department of agriculture, front line extension professionals of KVK's and NGO's and Scientists at one per cent level of probability.

However a detailed analysis shows that when three out of 12 personal factors and expert system's attributes were positively and significantly correlated to the attitude of extension professionals of SDA towards agri-expert systems; seven out of 12 personal factors and expert system's attributes were positively and significantly correlated to the attitude of front line extension personnel and scientists towards agri-expert systems at one per cent level of probability. When, 'availability, timeliness, innovative proneness, training, information content, accuracy and relevancy' were personal factors and expert system's attributes influencing the attitude of front line extension professionals towards expert system; 'availability, innovative proneness, information content, timeliness, accuracy, training and accessibility' were the personal factors and expert system's attributes that influenced the attitude of scientists. In case of frontline extension personnel, format clarity was positively and significantly related to the attitude at $5 \%$ level of probability.

Training on Information Communication Technologies were the best and reliable sources for developing attitude towards agri-expert systems. Extension professionals from SDA, front line extension personnel from KVK and NGO's and scientists perceived that training programmes on ICT tools helped to attain more knowledge which in turn develops favourable attitude towards agri-expert systems and hence positive and significant relationship. Innovative proneness of all three categories of respondents was an important attribute for developing attitude towards agri-expert systems. This might be because most of the people always have urge to do new things and attain new achievements which helps to develop favourable attitude towards agri-expert systems. Availability of agri-expert systems to the respondents was an important attribute for developing attitude towards agri-expert systems. This might be because most of the respondents were having desktop or laptop in their home or office. KAU expert systems are available in off-line forever once after down loaded from the website which helped to develop favourable attitude towards agri-expert systems. Accessibility of agri-expert systems by the scientists was influencing the attitude towards agri-expert systems. This might be because most of the respondents perceived agri-expert system to be easy to access, use and get the needed information. Relevancy of agri-expert systems by the scientists was influencing the attitude towards agri-expert systems. This might be because most of the respondents felt that 
agricultural expert system could serve the information needs of users like researchers, extension professionals, scientists, students and farmers which enhance the attitude of respondents towards agri-expert systems. Information content of agriexpert system was an important attribute which can influence the attitude of respondents towards agri-expert systems. Extension professionals from SDA, front line extension personnel from KVK and NGO's and scientists perceived that information content of agri-expert systems was complete and understandable to the users which develops favourable attitude towards agri-expert systems. Timeliness of the information from agri-expert systems was an important attribute for developing attitude towards agri-expert systems. This might be because most respondents felt that the users could locate the information easily and it consumed less time which develops favourable attitude towards agri-expert systems. Accuracy of the information from agri-expert systems was an important attribute for developing attitude towards agri-expert systems. This might be because most respondents presumed that agriexpert system would provide greater information support for taking suitable decisions with greater accuracy which develops favourable attitude towards agri-expert systems.

\section{Conclusion}

Results showed that more respondents belonged to moderately favorable attitude category and the factors such as training, Innovative proneness and Information content were positively and significantly related with attitude of extension towards expert systems among all three categories of respondents. However there were respondents possessing un favorable attitude towards agri-expert systems. This un favorable attitude towards agri-expert systems should be abridged by augmenting the factors like; relevancy, retrievability, accessibility, availability, credibility of agri-expert systems with accurate, correct and timely information.

\section{References}

Abdel-wahed, M.A.M., 2007. A Futuristic Study on the e-extension in Egypt. Dissertation, Agricultural Extension, Faculty of Agriculture, Assiut University, Egypt, 174.

Amir, A., 2012. Agricultural extension workers attitude to and experience of e-learning. African Journal of Agricultural Research 7(24), 3534-3540.

Anand, K., Ravichandran, V., 2014. A Scale to Measure the Attitude of Extension Personnel towards the Information and Communication Technology (ICT) Tools. Trends in Biosciences 7(17), 2583-2585.

Chetsumon, S., 2005. Attitudes of extension agents towards Expert systems as decision support tools in Thailand. Dissertation, Lincoln University, Thailand, 256.

Jones, G.E., 1997. The history, development and future of Agricultural Extension in improving Agricultural Extension-A reference manual, FAO, Rome, 208.

Ndubisi, N., 2004. Factors influencing e-learning adoption intention: Examining the determinant structure of the decomposed theory of planned behaviour constructs. Dissertation, University Malaysia Sabah, F.T. Labuan, Malaysia, 223.

Nitin, K., Binod, K., Keshao, K., 2013. An expert system approach for improvement of agriculture decision. International Journal of Artificial Intelligence and Expert Systems 5(1), 8-12.

Patterson, D.W., 2004. Introduction to Artificial Intelligence and Expert Systems. Prentice-Hall: New Delhi, India, 356.

Rolling, N., 1980. Extension Science-Information Systems in Agricultural Development. New York: Cambridge, 325.

Shashaani, L.B., 1994. Gender-differences in computer experience and its influence on computer attitudes. Journal of Educational Computing Research 11(4), 347-367. 